here some years ago, could not put off or on her gown by herself, consulted me about another ailment-she is now 80 years of age. I was delighted to find her shoulder-joint all right, the undoubted result mainly of skilled massage aided by the internal use of the sulphur waters and the outward application of baths and warm douches. What would have been the condition of this lady's arm non: I leave to your readers to imagine, had the complaint not been taken in hand and strenuously treated at an early stage.

I am, Sirs, yours faithfully

Strathpeffer, Oct. 27th, 1906 . WM. BRUCE, M.D. Aberd.

\section{THE RELATION OF DENTAL CONDITIONS TO PULMONARY TUBERCULOSIS.}

\section{To the Editors of THE LANCET.}

SIRS,-In your annotation in THE LANCET of Oct. 20th on the above subject you deal with the interesting conclusions of Mr. F. L. Dodd and Mr. H. B. Ezard as to oral sepsis in consumptives and its causes. These results, of course, give rise to speculations as to the evidence they afford of generally depressed health, whether from weakness of constitution or unfavourable surroundings, as also of that tendency to decalcification described by French observers. They naturally suggest, too, indications-which, in my experience of sanatoriums, are, having regard to practical considerations, fairly well recognisedfor treatment. But may I suggest to $\mathbf{M r}$. Dodd and $\mathrm{Mr}$. Ezard that the share which dental surgery may claim in the treatment of pulmonary phthisis does not begin and end with the conditions they describe? If they will devote their skilled attention to the matter they will find, I am sure, mush more readily than was done lately (as described in the British Medical Journal, June 16th, 1906), that the proportion of those showing protrusion and irregularity of the upper teeth (with consequent inability to keep the lips closed) is much higher in consumptives than in the non-tuberculous. In fact, I think they will be led, as I was, to the conclusion that undue oral respiration is, to say the least, a very common antecedent to pulmonary phthisis.

Two cases of possible interest to dental surgeons may be quoted. The first was a man who had probably suffered from adenoids in childhood, for he was "overhung" and had the narrow palate, collapsed nostrils, and chronic mouthbreathing associated with that complaint. When, some years before falling ill with phthisis, he was provided with false teeth, one natural tooth only was left in the front of the upper jaw. It was a "buck" tooth, projecting at an angle which made it impossible for the upper lip to close over it, except by a distinct muscular effort. The artificial denture had been made to conform to this tooth with the result that normal nasal respiration, which might perhaps have been furthered by another arrangement-here, of course, I speak as a layman-was henceforth for this man out of the question. In the second case oral respiration was a good deal checked by the replacement of a single projecting tooth by an artificial one in line with its neighbours. The matter does not end with treatment, of course. It is believed that an important part of the future prophylaxis of pulmonary phthisis will be the promotion of normal nasal respiration ; and that in such promotion rhinology and dental surgery will take a large share.

I am, Sirs, yours faithfully,

Crossley Sanatorium, Oct. 21st, $1906 . \quad$ W. C. RIVERS.

\section{LEPROSY SEGREGATION IN CAPE COLONY.}

To the Editors of THE LANCET.

SIRs,-Will you allow me to avail myself of your worldwide circulation in order to draw the attention of all whom it may concern to the fact that the attempt to repress leprosy in Cape Colony by compulsory segregation has proved a lamentable failure. The report of the Health Department for the Colony for the years 1904-05 is now before me and it has doubtless been sent to you also. The chapter devoted to leprosy is a melancholy one. It admits that the disease is steadily increasing; that Robben Island and the Emjanyana Asylum are no longer adequate to receive those whom the law empowers them to claim. The demand is now made for more of these leprosy prisons. I can call them by no milder name than "prisons," for their inmates are captured by the police and, with but very few exceptions, ars confined for life. It is exactly a century and a balf ago since the first sufferers from leprosy in the Colony were recognised. They were on a Datch farm near to Capetown, and were only three in number. The use of salted fish as food had become common a little earlier and was increasing every year. In the early part of last century under English rule a small voluntary segregation ho ne was formed in an inland valley "Hemelen-Aards," not far from the capital. Between 1816 and 1845 500 patients were admitted there. In the iatter year additional accommodation was obtained on Robben Island, and in 1892 an Act was passed enabling the authorities to apprebend all subjects of the disease and deport them to that desolate spot. That Act was rathlessly carried out and from that time onward from five to six hundred victims of it have been resident there. This number has been maintained in spite of a very heavy mortality and with the result that in addition to those under confinement upwards of a thousand of leprosy patients are now at large in the colony for want of accommodation for their confinement.

In my book on "Leprosy and Fish-eating" I ventured, I fear almost rudely, to compare those who would enforce segregation to the wise men of Gotham who built an enclosure in which to keep a cuckoo. The bird flew over the wall. "But," said they, "it only just got over ; if we had built a yard higher it could not have got out." And so they went on year after year building higher and higher but without success. This, so far as I understand the question, is precisely what the Cape Colony authorities have done and still wish to persevere in doing. Hemel-en-Aards was not big enough and Robben Island was inaugurated and it being not enough Emjanyana was constituted and to it was added an asylum at Pretoria. After adducing figures, which show that the disease has been steadily increasing all over the Colony, the medical officer of health sums up: "At the present time there cannot be less than a thousand lepers at large," and adds "The cause of this large number of unsegregated lepers is the total inadequacy of the present asylum accommodation." $\mathrm{He}$ further writes: "The Leprosy Repression Act has now been in force for the last 15 years, but, so far, no sensible diminution of the stream of lepers annually coming to light has been made by its operations." Yet additional facilities for "repression" are urgently demanded and no other measures are even dis cussed. Are the authorities of Cape Colony one whit wiser than their predecessors of Gotham?

I am, Sirs, yours faithfully,

Cavendish-square, Oct. 24th, 1906. Jonathan HuTChINson.

\section{CINNAMON OIL IN THE TREATMENT OF INFLUENZA.}

To the Editors of THE LANCET.

SiRS, - I notice in the daily press that the learned in such matters are prophesying that we may probably have to undergo another visitation of influenza this autumn, and as these vaticinations may possibly turn out to be correct I am prompted to ask you to allow me space in your columns again to call the serious attention of your readers to the excellent results that, as far as I can judge, follow if influenza is treated systematically with cinnamon oil.

For nearly 16 years I have employed cinnamon in various forms in treating this disease, but for many years now I have always used the oil of Ceylon cinnamon bark. There is another oil of cinnamon on the market, extracted, I believe, from the leaves of the plant, which though rather cheaper should be avoided and the oil of cinnamon bark only should be used. We all of us have heard only too often of sad cases of influenza where the unhappy patients have been confined to their beds or their rooms for a fortnight, three weeks, a month, or even longer. Such a long detention on the sick list cannot be a pleasant experience and I am perfectly convinced that it ought never to occur. I employ these words advisedly. For I altogether decline to believe it can be ascribable only to a singular series of coincidences that now for nearly 16 years, during which time I have in variably treated influenza with cinnamon, my patients have generally been perfectly fit to return to their avocations, whatever they may have been, within three or four days and that in no single case has a patient suffering from 
influenza been on my hands for more than the inside of a week.

The treatment for which I suggest a fair trial, and which I invariably adopt, is abundantly simple and is as follows. Let the influenza patient take 12 drops of cinnamon oil and repeat the dose in an hour; two hours after this second dose let the patient take ten drops of the oil, and then let him go on taking ten drops every two hours without intermission till the temperature falls to normal. And after the temperature has fallen to normal, or possibly a little under, let the patient take ten drops of the oil three times a day for a day or two. In every disease, probably, the sooner the patient is placed under treatment the better, and this is pre-eminently the case in influenza. And if a patient suffering from this disease is systematically treated with cinnamon oil in the manner above described within three or four hours from the onset of the disease I think it will probably be found that the temperature will have returned to normal within 12 hours; but if the patient is not put under treatment for a couple of days it will probably be at least 24 or 30 hours before the temperature becomes normal. After the temperature has fallen to normal the patient should remain in his room for at least 24 hours and if possible should remain indoors for a further period of two or three days. But many cases that had been submitted early to treatment, cases of robust persons under 40 years of age and whose engagements were pressing, I have permitted to return to their occupations after only 24 hours' rest, and so far without any untoward result. But I always advise that patients should remain indoors for two or three days if they possibly can. Especially should they be urged to do so in those cases where the disease has been allowed to run for a day or two before being submitted to treatment. Each dose of cinnamon oil should be taken in half a wineglass or a wineglass of water to lessen its pungent taste.

It is hardly necessary for me to add, perhaps, that Ceylon cinnamon bark oil can be easily obtained from any respectable druggist in any town.

I am, Sirs, yours faithfully, Joseph Carse Ross, M.D. Edin.

Withington, Manchester, Oct. 23rd, 1906.

\section{"GRAPH" PAPER.}

To the Editors of THE LANCET.

SIRS,-May I call the attention of those of your readers who are interested in school hygiene to the evils likely to accrue to the eyesight of school children from the use of "graph" paper? Even under the most favourable conditions of light and posture and with the best of eyesight the ocular strain involved in counting the squares is intense, and I am sure that where such conditions do not exist the children are having sown for them the seeds of future trouble. The use of "graph" paper is now customary even in preparatory schools; and boys of 12 years or under are set work requiring the closest attention to secure accurate results. It certainly seems a retrograde step, now that the printing of school books has so improved, to make this new demand on the eyesight of the young. Moreover, the evils so often complained of in the use of small type are accentuated in this solving of problems on squared paper, as in the former case the eye does not take exact account of each separate letter after the art of reading has once been acquired, whereas in the latter each square bas to be individually appreciated. As the squares are uniform there is no rest for the eye, and one moment of relazation necessitates a recount-i.e., a renewal of the strain. I inclose for your inspection two samples of graph paper now in the market. You will see that the squares are respectively one square millimetre and less than ${ }_{10}^{1}$ th of a square inch.

I am, Sirs, yours faithfully, MoNTAGUE PIIKIN, B.A., M.R.C.S.

Earleywood School, Ascot, Oct. 29th, 1906.

\section{COMPRESSED DRUGS.}

To the Editors of THE LANCET.

SIRS, - The steady decrease of the general practitioner's income is no doubt due to a variety of reasons, but most certainly the reckless ordering of "tabloid" preparations is one for which the medical man is solely responsible. $\mathrm{He}$ orders them in the first instance either verbally or by pre-
scription; they are obtained by the pstient in the original bottles, the word tabloid being stamped upon each one, and are readily re-obtained at any druggist's or stores by man, woman, or child.

By ordering tabloids the practitioner is not only damaging his own practice but is giving an excellent advertisement to a proprietary brand, and is acting as a first-rate "traveller" to the wholesale firm whose goods he so constantly pushes. If compressed drugs are desired let them be prescribed as tabelle; do not specify any particular brand but rather send the patient to a reliable pharmacist. We are entirely responsible for the introduction of tabloids; let us become responsible for their disappearance. I am, Sirs, yours faithfully,

Aigburth, Liverpool, Oct. 27th, 1906. WILLIAM B. BENNETT.

\section{THE CONGRESS AT MILAN AND THE TREATMENT OF INSANITY IN ITALY.}

(From a Correspondent.)

SINCE her unification the mental activity of Italy has been astonishing and her contributions to medicine have brought her into the first rank. Let us call to mind how the causes of malarial fever have been explored by the physicians of Rome working alongside of our medical officers in India. My friend the late Dr. Thomas Charles retired from the Indian Army and long practising at Rome acted as the medium of communication between these two distant bands of workers. In the department of psychiatry the contribu. tions that have come from Italy are of the first importance. We have only to allude to the researches of Tamburini and Seppilli on the localisation of the functions of the brain, those of Luciani on the cerebellum, of Albertoni on epilepsy, the microscopic studies of Golgi, the works of Giacomini on the convolutions of the brain and on microcephaly, and the numerous books of Lombroso on criminal anthropology and the pathology of insanity. It was therefore assured that the meetings of the Congress for the Care of the Insane announced to be held at Milan from Sept. 26th to 30th would be attended by many distinguished visitors. Milan, which now counts more than half a million of inhabitants, is the centre of the industrial and much of the intellectual life of Italy. Since the opening of the International Exhibition in April last there has been a great concourse of sightseers and the Milanese have sagaciously taken advantage of the many erudite visitors to o'ganise congresses from the "conclusions" of which they gain light on different questions of the day. About a dozen congresses were reported in the daily journals. The most important was the Congresso Internazionale per l'Assistenza degli Alienati, which has already held meetings at Antwerp and Paris. The managing committee with its active secretaries, Dr. G. C. Ferrari and Dr. P. Gonzalez, had arranged that a reduction of from 40 to 60 per cent. should be allowed on the railway fares of the congressists. Unhappily they could not prevent the hotel keepers from doubling their charges, and they had to exert themselves to procure accommodation for the 300 members of the Congress. The larger proportion were Italians, but there were many French, owiss, and Belgians, 30 German medical men, and representatives from other countries of Europe and America. The foreign languages allowed were French, German, and English, but readers of papers in these two last were little listened to.

I may remind your readers that in his opening address to the Twelfth Congress of the Societ ì Freniatrica Italiana held at Genoa in 1904, the President, Dr. Augusto Tamburini, congratulated the society that it had secured the passing of a law which withdrew the care of the insane from the bonds of the old local customs and laid down general rules for the whole of Italy. For this they had to thank the exertions of the society and the powerful aid of Professor Leonardo Bianchi in getting the several clauses passed through committees and finally through the Chamber of Deputies. By this law the power of the superintendents to regulate the organisation of the asylum has been clearly defined and established, the proportion of assistant physicians increased, and special instruction for the last rendered obligatory. Dr. Tamburini admitted that this would entail increased expenses but held out the expectation that these might be repaid by a larger number of recoveries. This hopeful view has bee $n$ scarcely favoured by experience. The number of the insane 